\title{
Foaming of Polylactic Acid/Cellulose Nanocrystal Composites: Pickering Emulsion Templating for High-Homogeneity Filler Dispersions
}

\author{
Yunchong Zhang, Joost Duvigneau,* Xiaofeng Sui,* and G. Julius Vancso* \\ Cite This: ACS Appl. Polym. Mater. 2022, 4, 111-120 \\ Read Online
}

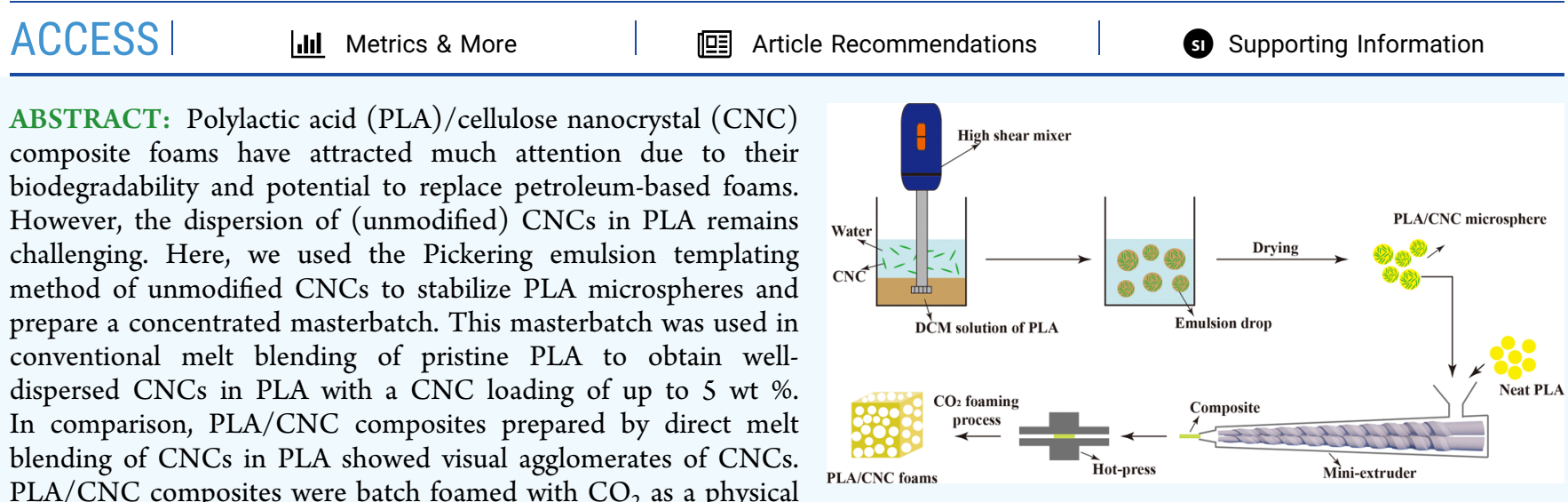
PLA/CNC composites were batch foamed with $\mathrm{CO}_{2}$ as a physical blowing agent. We demonstrate that the good $\mathrm{CNC}$ dispersion obtained by the Pickering emulsion route is favorable for preparing PLA foams with smaller and more uniform cell sizes and with a higher cell density. These results demonstrate that the Pickering emulsion approach to prepare CNC masterbatches for subsequent dispersion in thermoplastics by conventional processing seems promising for numerous industrial applications.

KEYWORDS: polylactic acid, cellulose nanocrystal, Pickering emulsion, masterbatch, dispersion, foaming

\section{INTRODUCTION}

Polymer foams are widely used in many fields, such as food packaging, building construction, transportation, electronics, and so on, due to their lightweight, thermal and sound insulating, and impact energy dissipating properties. ${ }^{1-4}$ At present, most polymer foam products consist of petroleumbased materials, such as polystyrene (PS), polyurethane (PU), poly(vinyl chloride) (PVC), and poly (methyl methacrylate) (PMMA) foams. To achieve biodegradability and to recycle these systems remains a grand challenge. In addition, the unavoidable fossil resource depletion and increasing environmental concerns direct researchers to develop biodegradable polymer foams to replace currently used petroleum-based materials. $^{5-8}$

Polylactic acid (PLA), an aliphatic thermoplastic polyester, is produced from renewable resources, such as cornstarch and sugarcane. ${ }^{9,10}$ PLA has attracted significant industrial and academic interest over recent years, which is attributed to its biodegradability, biocompatibility, and good mechanical properties. $^{11}$ Therefore, PLA is considered a promising substitute for some petroleum-based foamed products. ${ }^{12}$ However, PLA has several disadvantages, i.e., low melt strength, poor thermal resistance, and brittleness, which significantly limit the commercial exploitation of PLA-based foams. ${ }^{13,14}$ Some strategies to improve PLAs' foaming behavior and foam properties include blending with other polymers, ${ }^{15,16}$ introducing a long-chain branched structure, ${ }^{17}$ cross-linking, ${ }^{18}$ coblowing agents, ${ }^{19}$ and adding particles. ${ }^{20}$ Among these methods, the addition of particles is a well-known, practical, and straightforward way to improve PLAs' foaming behavior and foam properties. ${ }^{14,21,22}$

Nanocellulose, derived from renewable resources, is well known for its high strength, biocompatibility, and biodegradability. $^{23-25}$ Therefore, nanocellulose is considered a promising particle to improve the foaming behavior and foam properties of PLA when used as a Pickering emulsifier. During PLA foaming, well-dispersed nanocellulose particles can enhance the melt strength of PLA by forming a nanocellulose network in the PLA matrix by hydroxyl bonds and entanglements between them. ${ }^{26}$ Furthermore, nanocellulose could act as heterogeneous nucleation sites to increase the cell density of PLA foams. ${ }^{27}$ For instance, Park and co-workers ${ }^{23}$ reported the

Received: August 18, 2021

Accepted: November 25, 2021

Published: December 8, 2021 
preparation of PLA/cellulose nanofiber (CNF) composite foams. They studied the effect of added CNFs on the rheological and thermal properties of the foams and the composite foaming behavior. They observed that the addition of CNFs increased the viscosity of PLA in the low-frequency range of rheology measurements, led to higher cell densities, decreased cell sizes of the composite foams, and enhanced the crystallization kinetics of PLA.

The degree of nanocellulose dispersion in the PLA matrix significantly influences the PLA foam morphology and properties. During the foaming process, the foam cell nucleating efficiency of nanocellulose is decreased when particles are poorly dispersed in the PLA matrix. ${ }^{20}$ However, due to the poor compatibility of cellulose and PLA, it is difficult to disperse nanocellulose uniformly. ${ }^{28}$ Chemical surface modification of nanocellulose is a well-known and frequently applied strategy to improve its dispersion in PLA. ${ }^{29}$ For instance, $\mathrm{Wu}$ and co-workers ${ }^{30}$ compared the cell morphology and mechanical properties of PLA/cellulose nanocrystal (CNC) composite foams with three different types of CNCs, including pristine $\mathrm{CNC}$ and acetylated ones with lower and moderate degrees of substitution. The composites with acetylated CNCs had a better CNC dispersion than those with pristine CNCs. The mechanical properties and foaming behavior of foams were improved due to the enhanced CNC dispersion and increased affinity between CNC and PLA. Alternatively to chemical surface modification strategies, our group has developed a Pickering emulsion-based method to prepare nanocellulose polymer composites with a good particle dispersion. ${ }^{31-34}$ In the Pickering emulsion method, CNCs stabilize the PLA/ solvent-in-water Pickering emulsion, and subsequently, PLA/ CNC microspheres can be prepared by removing the solvent and water. Finally, a composite film is obtained by hot-pressing these microspheres. However, the Pickering emulsion method requires a typical particle loading exceeding $5 \mathrm{wt} \%$, which is relatively high for PLA/CNC nanocomposite foams. In addition, when processing the CNC-covered PLA micropowder obtained by the Pickering emulsion method, CNC-rich and CNC-poor domains form with preference when no additional mixing is applied. Therefore, in this paper, we report the extension of our earlier work to disperse pristine CNCs in PLA by first preparing a Pickering emulsion-based $\mathrm{PLA} / \mathrm{CNC}$ masterbatch with a CNC loading of $10 \mathrm{wt} \%$. In a second step, the CNC concentration is diluted to below 5 wt \% by conventional melt mixing of the masterbatch with PLA in an extruder. Melt mixing introduces additional dispersive forces that distribute CNCs homogeneously throughout the PLA matrix. The composites obtained were foamed by $\mathrm{CO}_{2}$ batch foaming. The batch foaming process is mainly used to identify the effects of material composition and foaming parameters on the polymer foaming behavior in lab-scale experiments. $^{35-37}$ We demonstrate that this straightforward method is very convenient to prepare PLA/CNC composites with a uniform particle dispersion without using the typically required particle surface modification strategies. In addition, we show that a good CNC distribution encompassing unmodified cellulose is beneficial in PLA foam cell nucleation and foam cell stabilization.

\section{EXPERIMENTAL SECTION}

Materials. Pellets (4060D) of polylactic acid (PLA), an amorphous polymer with an average D-lactide content of $12 \mathrm{wt} \%$ and a glass transition temperature $\left(T_{\mathrm{g}}\right)$ of $55-60{ }^{\circ} \mathrm{C}$, were supplied by Natureworks. Cellulose nanocrystals (CNCs) were purchased from CelluForce (Canada). Sodium chloride $(\mathrm{NaCl})$ and potassium hydroxide $(\mathrm{KOH})$ were obtained from Sigma-Aldrich. Dichloromethane ( $\mathrm{DCM}, \mathrm{CH}_{2} \mathrm{Cl}_{2}$ ) and methanol were obtained from VWR chemicals. All chemicals were used as received.

Preparation of PLA/CNC Composite Films. Pickering Emulsion Masterbatch Route. A 6 wt \% CNC dispersion was diluted with deionized water to form a $0.5 \mathrm{wt} \%$ cellulose dispersion. The CNC-to-PLA ratio in the Pickering emulsion was set to $10 \mathrm{wt} \%$ to prepare the PLA/CNC masterbatch. A solution of PLA in DCM $(30 \mathrm{~mL}, 90 \mathrm{mg} / \mathrm{mL})$ was added to the aqueous CNC dispersion $(60$ $\mathrm{mL}) . \mathrm{NaCl}(50 \mathrm{mM})$ was added to the aqueous phase to screen the surface charge of the CNC. The mixture was homogenized (IKA T18 homogenizer, Germany) at $12000 \mathrm{rpm}$ for $3 \mathrm{~min}$ to obtain Pickering emulsions. DCM was evaporated at ambient temperature for $24 \mathrm{~h}$. The precipitates were collected by vacuum filtration using a 500-mesh filter screen. The obtained PLA/CNC microspheres were vacuum dried at $60{ }^{\circ} \mathrm{C}$ for $24 \mathrm{~h}$. The dried microspheres were mixed with neat PLA pellets by a miniextruder (DSM) to dilute the CNC concentration and homogenize its distribution. The barrel temperature was set to $190{ }^{\circ} \mathrm{C}$, and the screw speed was $100 \mathrm{rpm}$. By this method, PLA/CNC composites with 1,3 , and 5 wt $\%$ CNC were prepared. Subsequently, PLA/CNC composite films $(20 \mathrm{~mm} \times 20$ $\mathrm{mm} \times 1 \mathrm{~mm}, L \times W \times H)$ were prepared by hot-pressing employing a hot press (Fontijne, The Netherlands) at $180{ }^{\circ} \mathrm{C}$ and $100 \mathrm{kN}$ for 5 $\min$.

Pickering Emulsion-Based Templating. A 6 wt \% CNC dispersion was diluted with deionized water to form a $0.25 \mathrm{wt} \%$ cellulose dispersion. The CNC-to-PLA ratio in the Pickering emulsion was set to $5 \mathrm{wt} \%$ to prepare the PLA/CNC Pickering emulsion-based composites. A solution of PLA in DCM $(30 \mathrm{~mL}, 90 \mathrm{mg} / \mathrm{mL})$ was added to the aqueous $\mathrm{CNC}$ dispersion $(60 \mathrm{~mL}) . \mathrm{NaCl}(50 \mathrm{mM})$ was added to the aqueous phase to screen the surface charge of the CNC. The mixture was homogenized (IKA T18 homogenizer, Germany) at $12000 \mathrm{rpm}$ for $3 \mathrm{~min}$ to obtain Pickering emulsions. DCM was evaporated at ambient temperature for $24 \mathrm{~h}$. The precipitates were collected by vacuum filtration using a 500 -mesh filter screen. The obtained PLA/CNC microspheres were vacuum dried at $60{ }^{\circ} \mathrm{C}$ for 24 h. PLA/CNC composite films $(20 \mathrm{~mm} \times 20 \mathrm{~mm} \times 1 \mathrm{~mm}, L \times W \times$ $H$ ) were prepared by hot-pressing the PLA/CNC microspheres in a hot press (Fontijne, The Netherlands) at $180{ }^{\circ} \mathrm{C}$ and $100 \mathrm{kN}$ for 5 min.

Direct Melt Blending Method. An aqueous 6 wt \% CNC dispersion was dried using a freeze-dryer (Freezone 4.5, Labconco) for 2 days. Dry CNC powder and PLA pellets were added to a miniextruder (DSM) to get PLA/CNC composites with 1,3 , and $5 \mathrm{wt}$ $\% \mathrm{CNC}$ loading. The barrel temperature was set to $190{ }^{\circ} \mathrm{C}$ and the screw speed was $100 \mathrm{rpm}$. PLA/CNC composite films $(20 \mathrm{~mm} \times 20$ $\mathrm{mm} \times 1 \mathrm{~mm}, L \times W \times H)$ were prepared by hot-pressing, employing a hot press (Fontijne, The Netherlands) at $180{ }^{\circ} \mathrm{C}$ and $100 \mathrm{kN}$ for 5 min.

Preparation of PLA/CNC Composite Foams. The obtained PLA/ $\mathrm{CNC}$ composite and neat films were saturated with carbon dioxide $\left(\mathrm{CO}_{2}\right)(40 \mathrm{bar})$ in an autoclave for $6 \mathrm{~h}$ at room temperature, followed by rapid depressurization. Subsequently, the $\mathrm{CO}_{2}$ saturated films were foamed for $20 \mathrm{~s}$ by immersing them in a water bath set at $40{ }^{\circ} \mathrm{C}$. Next, the samples were quenched in ice water. Finally, the foams were left to dry in the air for at least $12 \mathrm{~h}$.

Characterization. Scanning electron microscopy (SEM) (JSM6010LA and JSM-7610FPlus, JEOL, Japan) was used to measure CNC dispersion in the PLA matrix and observe the foam morphologies. Before SEM analysis, the samples were freeze fractured following cooling in liquid nitrogen for $5 \mathrm{~min}$. The cross sections of the composites were coated with a gold-palladium alloy for $40 \mathrm{~s}$. The electron acceleration voltage was typically $5 \mathrm{keV}$. The cell size and cell density were determined by Image J software.

Atomic force microscopy (AFM) (Bruker, Multimode 8, NanoScope 5 controller) was used to measure the dimensions of CNCs. AFM images were collected using the PeakForce tapping mode with a 
silicon tip (nominal tip apex radius of $8 \mathrm{~nm}$, NanoWorld, Switzerland) utilizing a cantilever of $125 \mu \mathrm{m}$ (NanoWorld, Switzerland) and a resonance frequency of $2 \mathrm{kHz}$. Scanning was performed in the air under ambient conditions $\left(21{ }^{\circ} \mathrm{C}\right.$ and relative humidity $\left.\sim 40 \%\right)$. Image processing was performed using NanoScope software (version $8.15)$.

The rheological properties of neat PLA and PLA/CNC composites were measured using a ThermoHaake-Mars 60 rheometer with parallel plate geometry $\left(25 \mathrm{~mm}\right.$ diameter) at $200{ }^{\circ} \mathrm{C}$. A frequency sweep from 0.01 to $10 \mathrm{~Hz}$ was carried out to study the storage modulus $\left(G^{\prime}\right)$ and complex viscosity $\left(\eta^{*}\right)$ of the composites at a constant deformation of $1 \%$.

The tensile properties of neat PLA and PLA/CNC composites were tested using a universal testing machine (UH6502, Youhong, China). The cross-head speed was $10 \mathrm{~mm} / \mathrm{min}$. Five specimens were measured for each set of samples.

The absorbed $\mathrm{CO}_{2}$ concentrations of neat PLA and PLA composites after $6 \mathrm{~h}$ saturation were obtained by measuring the weight of the samples before and after saturation using a balance (Mettler AT261 DeltaRange).

Differential scanning calorimetry (DSC) (PerkinElmer Pyris 1) was used to measure the crystallinity of neat PLA and PLA/CNC samples after $6 \mathrm{~h} \mathrm{CO}_{2}$ saturation. Aluminum pans were sealed under air with ca. $5 \mathrm{mg}$ of the sample. The samples were heated from 30 to $200{ }^{\circ} \mathrm{C}$ and the heating rate was $10^{\circ} \mathrm{C} / \mathrm{min}$.

The cell density $\left(N_{\mathrm{v}}\right)$ of the foams was calculated by Kumar's theoretical approximation. ${ }^{38}$ No direct measurements of cell dimensions over the micrograph are required in this method; only the micrograph area $(A)$ and the total number of cells $(n)$ contained therein should be measured. Together with the magnification factor of the micrograph $(M), N_{\mathrm{v}}$ can be calculated according to eq 1

$$
N_{\mathrm{v}}=\left[\frac{\left(n M^{2}\right)}{A}\right]^{3 / 2}
$$

\section{RESULTS AND DISCUSSION}

$\mathrm{PLA} / \mathrm{CNC}$ composite films with different $\mathrm{CNC}$ concentrations were prepared by the Pickering emulsion masterbatch route, as shown in Figure 1a. In a first step, PLA/CNC composite microspheres with a high CNC concentration (10 wt \%), to serve as a masterbatch, were made by Pickering emulsionbased templating. Second, through melt blending by a miniextruder, PLA/CNC composites with dispersed CNCs at particle loadings below 5 wt \% were prepared by blending the PLA/CNC masterbatch with neat PLA. This route is referred to as the Pickering emulsion masterbatch route. Finally, composite films were made by hot pressing. Next, neat PLA and PLA/CNC composites were foamed using a two-step $\mathrm{CO}_{2}$ batch foaming process (Figure $1 \mathrm{~b}$ ).

CNC Dispersion in the PLA Matrix. As we will show later, the quality of CNC dispersion in the PLA matrix has a significant influence on the PLA foamability and foam properties. Figure 2 shows a photograph of neat PLA and PLA/CNC composite films prepared by (i) Pickering emulsion masterbatch route, (ii) direct melt blending, and (iii) Pickering emulsion-based templating for various CNC loadings. No visible CNC aggregation is observed in the PLA/CNC composite films prepared by the Pickering emulsion masterbatch route. Before melt blending, CNCs were evenly distributed at the surface of PLA microspheres (masterbatch). ${ }^{39}$ Furthermore, the PLA/CNC composite films prepared using only Pickering emulsion templating show a good CNC dispersion, which is consistent with our previously reported results. ${ }^{31}$

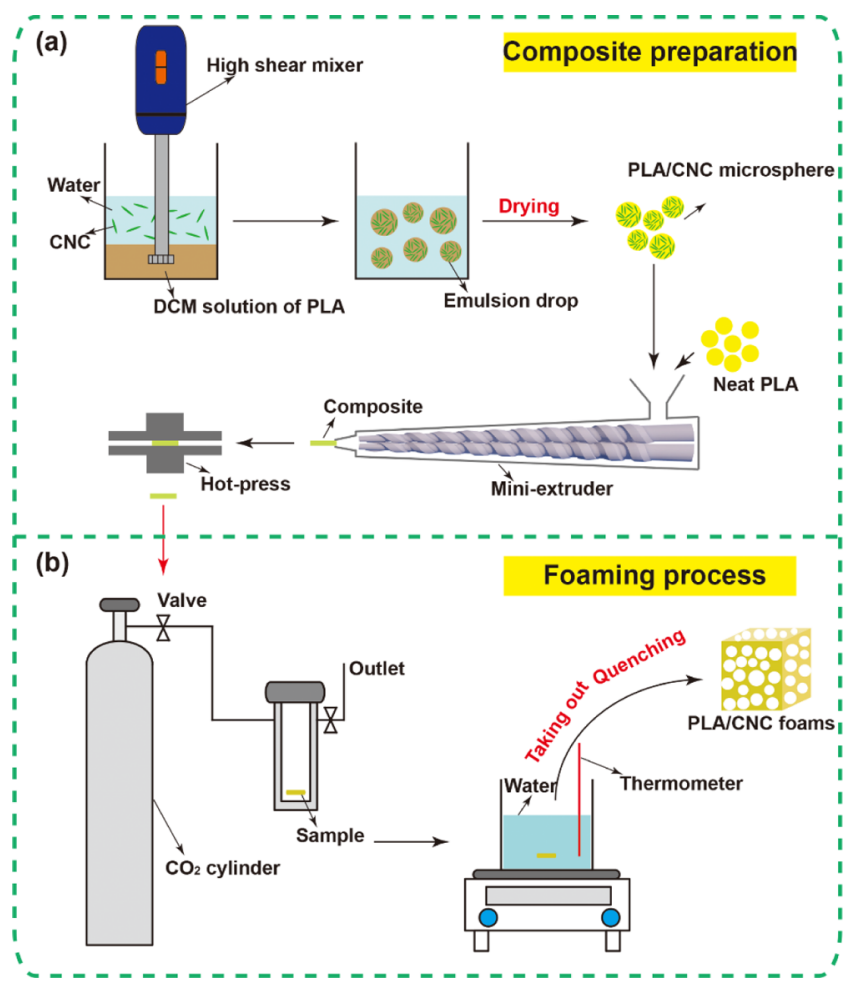

Figure 1. Schematic of the PLA/CNC composite film preparation method (a) and two-step $\mathrm{CO}_{2}$ batch foaming process (b).

However, many CNC aggregates are observed in the PLA/ CNC composite films when using direct melt blending to prepare the composites. Some CNC agglomerates formed during the freeze-drying process and simple melt blending was insufficient to break these agglomerates. This observation agrees with the results reported by Bendahou and co-workers ${ }^{40}$ for the dispersion of unmodified CNC powder in PLA by extrusion blending.

Furthermore, it is observed that the PLA films became slightly yellowish after the addition of CNCs. This is attributed to the low thermal stability of CNCs with sulfonate groups, which undergo thermal degradation during the extrusion process. ${ }^{41}$ Although the processing temperature is not as high as the onset temperature of $\mathrm{CNC}$ degradation $\left(\sim 220^{\circ} \mathrm{C}\right)$, the thermal shear experienced by CNCs during twin-screw extrusion is expected to induce CNC degradation. This may explain why the composite films prepared by the Pickering emulsion masterbatch route are more colored compared to the films prepared by Pickering emulsion-based templating and subsequent compression molding.

To further investigate CNC dispersion in the PLA matrix, the cross sections of PLA/CNC composites with 5 wt \% CNC content prepared by different methods were observed by SEM. SEM images are shown in Figure S1. In the SEM images of composites prepared by the Pickering emulsion masterbatch route (Figure S1a,b), no visible $\mathrm{CNC}$ agglomerates are present, indicating that CNCs were well dispersed in the composite. In SEM imaging, there is no contrast between the dispersed CNCs and the PLA matrix. Therefore, we could not resolve the few tens of nanometer thick and several hundred nanometer long CNCs even in high-resolution SEM imaging, as shown in Figure S1b (Figure S2 shows AFM images of the used CNCs deposited on silicon substrates). However, in the SEM images of the composites prepared by the direct melt 


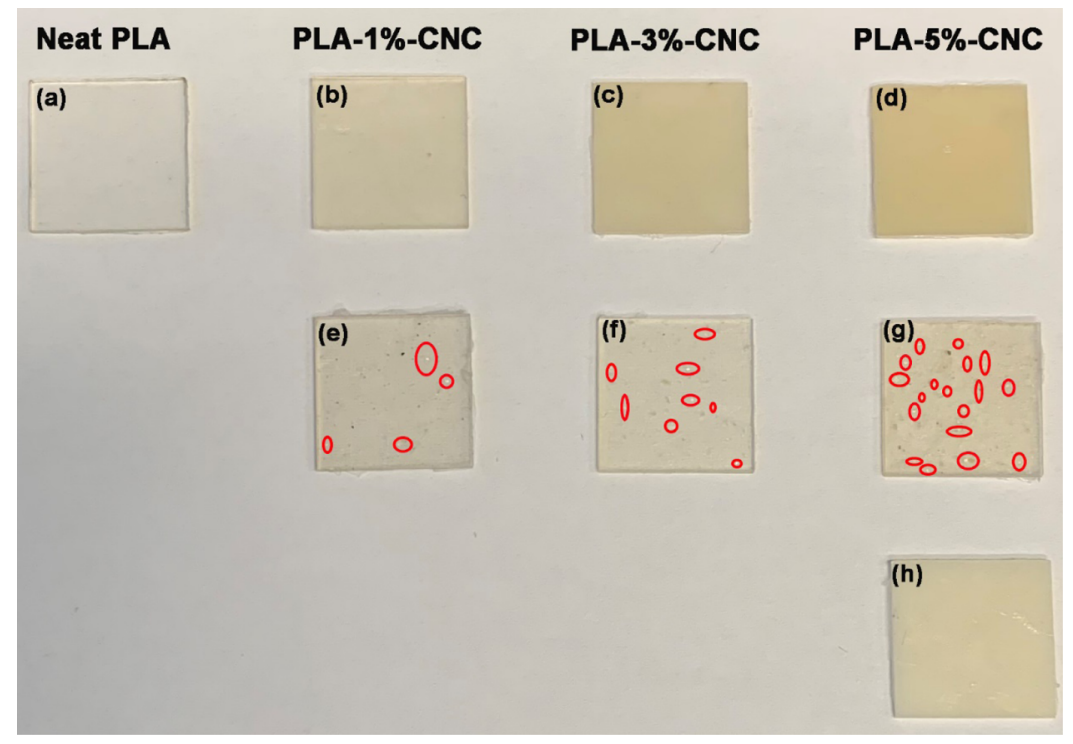

Figure 2. Photograph of PLA/CNC composite films with different CNC contents (up to $5 \mathrm{wt} \%$ ) prepared by the Pickering emulsion masterbatch route $(\mathrm{a}-\mathrm{d})$, direct melt blending $(\mathrm{e}-\mathrm{g})$, and Pickering emulsion-based templating $(\mathrm{h})$. Some visually observable CNC agglomerates are enclosed in the red circles.
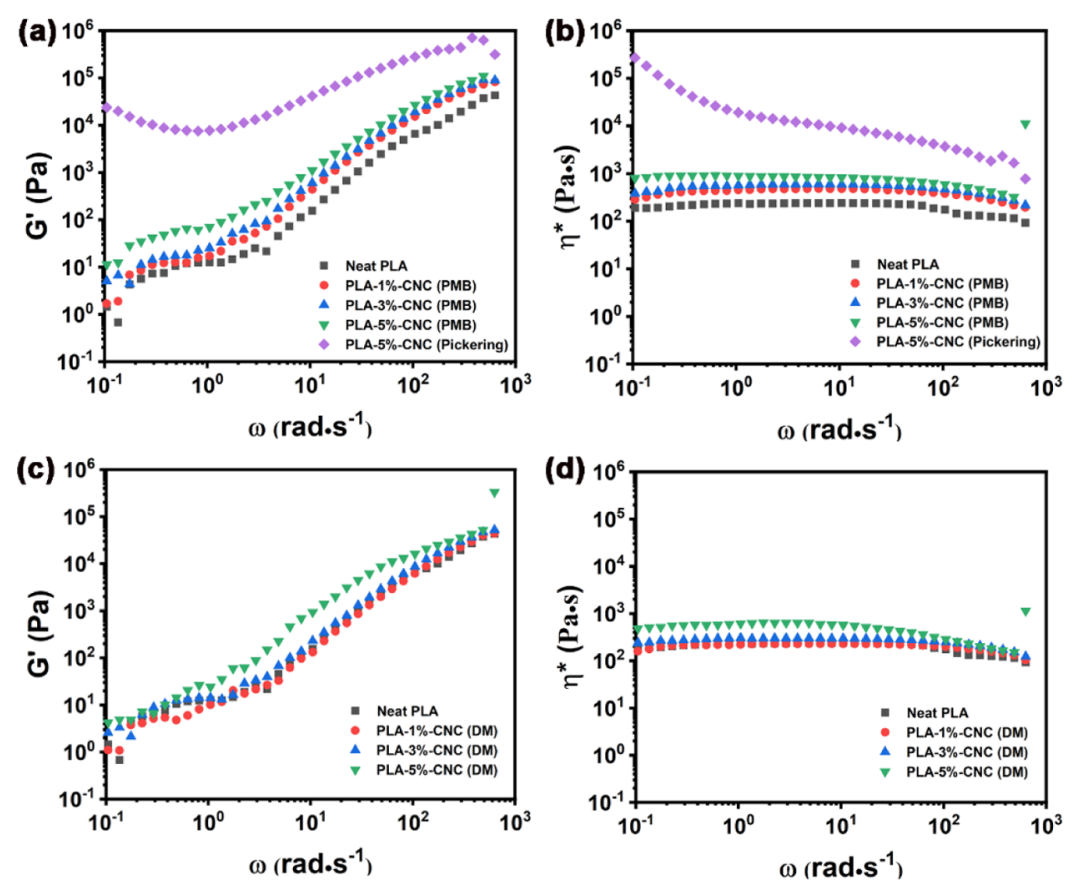

Figure 3. Values for storage modulus (a, c) and complex viscosity (b, d) of neat PLA and PLA composites prepared by the Pickering emulsion masterbatch route (PMB), the direct melt blending method (DM), and Pickering emulsion-based templating (Pickering).

blending method (Figure S1c,d), CNC agglomerates are readily observed. This indicates that the CNC agglomerates in the freeze-dried powder are not easily broken up and become dispersed by just melt blending. The storage modulus and complex viscosity of the composites prepared by different methods were measured by rheological measurements. As shown in Figure $3 \mathrm{a}, \mathrm{b}$, the storage modulus and complex viscosity of the composites prepared by the Pickering emulsion masterbatch route increased upon increasing the CNC content, indicating the good CNC dispersion in the PLA matrix. In contrast, the composites with 1 and 3 wt \% CNC content prepared by direct melt blending had a similar storage modulus and complex viscosity compared to the neat PLA, which is readily explained by the poor CNC dispersion in the PLA matrix. These results are in agreement with the observed CNC dispersion by optical and electrical microscopy. The storage modulus and complex viscosity of the composites with $5 \mathrm{wt} \% \mathrm{CNC}$ prepared by Pickering emulsion-based templating were significantly increased compared to the values for the composites with the same CNC content prepared by other methods. This may be due to the CNC network formed by the Pickering emulsion process and subsequent hot pressing. ${ }^{31}$ The tensile properties of the composites prepared by the Pickering emulsion masterbatch route are shown in Figure S3. The tensile strength of the composites was improved at low CNC contents ( 1 and $3 \mathrm{wt} \%$ ) due to the reinforcing effect of 

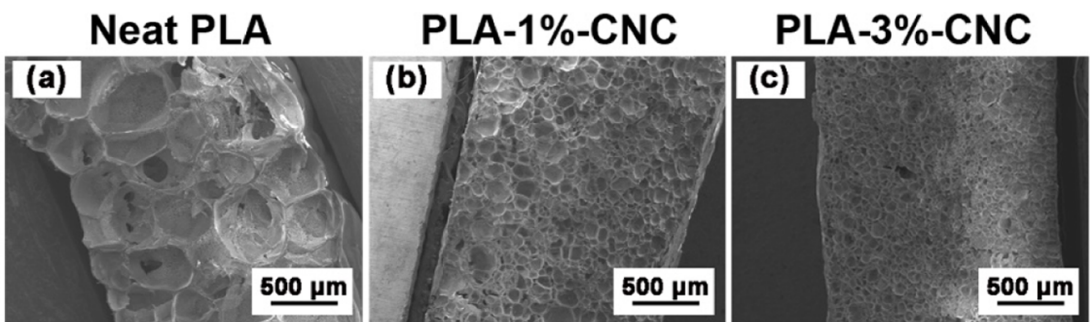

\section{PLA-5\%-CNC}
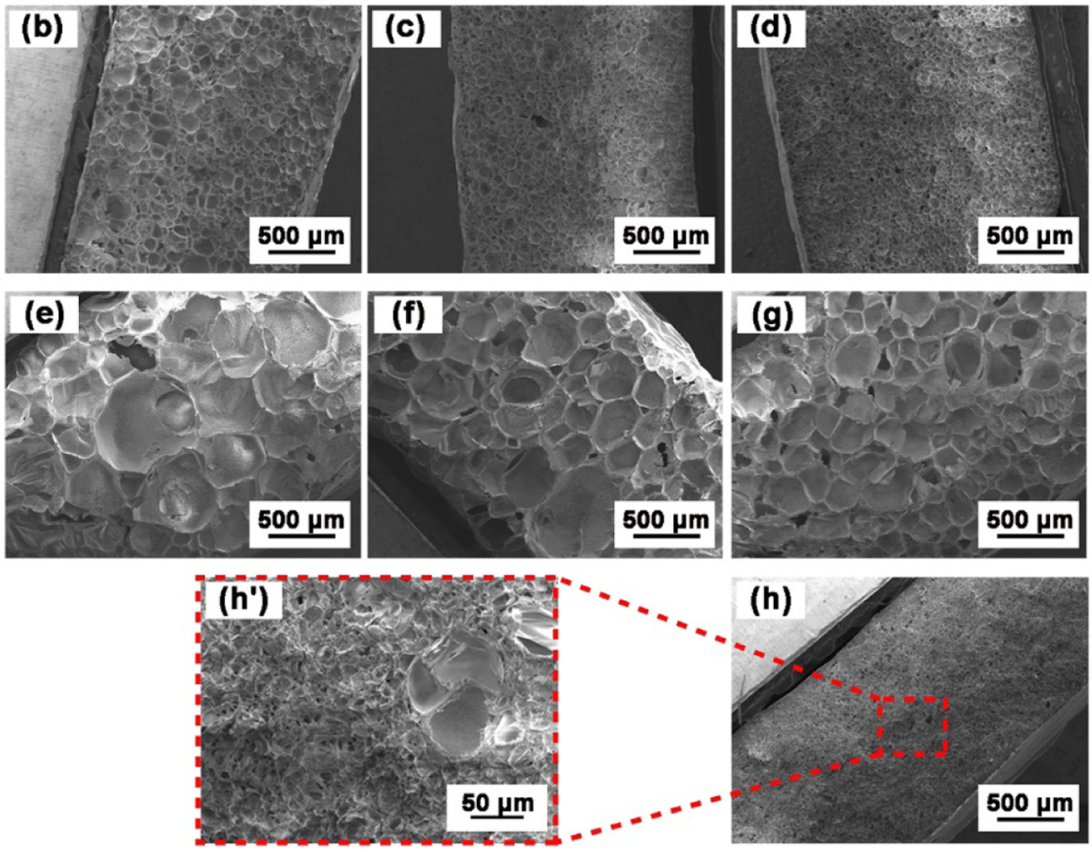

(h)

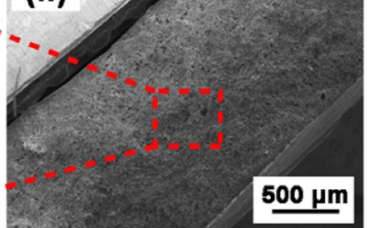

Figure 4. SEM images of cross-sectioned PLA/CNC composite foams with different CNC contents (up to 5 wt \%) prepared by the Pickering emulsion masterbatch route $(\mathrm{a}-\mathrm{d})$, direct melt blending $(\mathrm{e}-\mathrm{g})$, and Pickering emulsion-based templating $(\mathrm{h}$ and h').
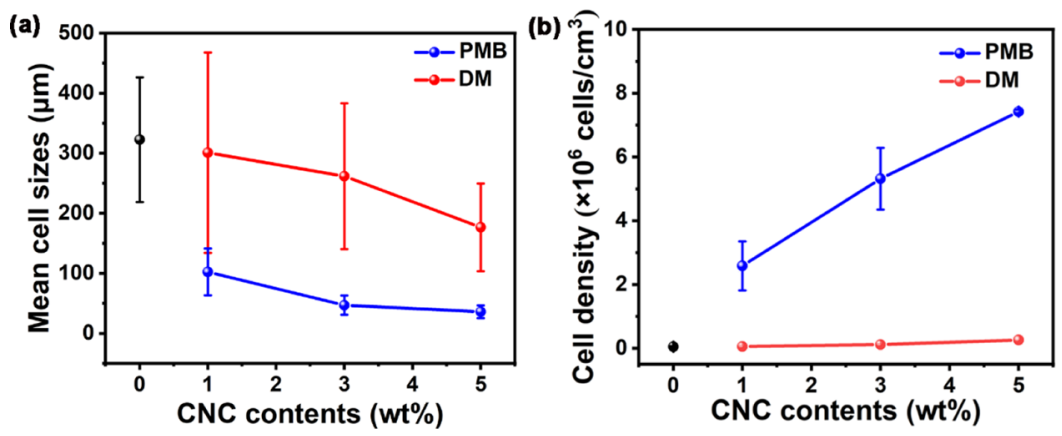

Figure 5. Mean cell size (a) and cell density (b) of PLA/CNC composite foams of composite films prepared by the masterbatch route (PMB) and direct melt blending (DM) as a function of the CNC content.

CNCs. However, when the CNC content was 5 wt \%, the tensile strength decreased due to the bad compatibility between PLA and CNC. The elongation at break decreased for all composites due to the rigidity of CNCs.

PLA/CNC Composite Foaming: Influence of CNC Dispersion. PLA/CNC composites prepared by different methods were foamed by a two-step $\mathrm{CO}_{2}$-based batch foaming process. The $\mathrm{CO}_{2}$ uptake of $\mathrm{PLA} / \mathrm{CNC}$ composites with a CNC content between 0 and 5 wt $\%$ after $6 \mathrm{~h}$ of $\mathrm{CO}_{2}$ saturation at 40 bar is shown in Figure S4. The $\mathrm{CO}_{2}$ concentration after saturation was around 20 wt \% for all samples. The modest decrease in $\mathrm{CO}_{2}$ uptake ( 1.5 wt \%) upon increasing the $\mathrm{CNC}$ concentration is attributed to the highly crystalline nature of CNCs, which prevents $\mathrm{CO}_{2}$ absorption by CNCs in the PLA matrix.

Upon saturation with $\mathrm{CO}_{2}$, PLA becomes plasticized, which for some PLA grades may induce crystallization. ${ }^{21}$ It is known that PLA crystals can act as heterogeneous foam cell nucleating agents $^{42}$ and/or may limit the subsequent cell growth during batch foaming. Therefore, we performed DSC measurements of PLA/CNC samples after saturation with $\mathrm{CO}_{2}$ for $6 \mathrm{~h}$ to determine whether PLA became partially crystallized before foam cell nucleation. The corresponding DSC results are shown in Figure S5. In the first DSC heating traces, no melting peaks were observed for PLA/CNC composites, indicating that no PLA crystals formed during $6 \mathrm{~h} \mathrm{CO}_{2}$ saturation. Noteworthy is that the glass transition temperatures of PLA/ CNC composites are higher than that of neat PLA. This is because the dispersed CNCs decrease the mobility of PLA chains. $^{31,43,44}$ The lower mobility of PLA chains would help to reduce the foam cell expansion as well.

Following saturation with $\mathrm{CO}_{2}$, foam cells in PLA/CNC composites were nucleated and the material became foamed. The following section will present and discuss the effect of the quality of CNC dispersion in the PLA matrix on the foaming behavior and foam morphology.

Figure 4 shows SEM images of cross-sectioned neat PLA and PLA/CNC composite foams. The corresponding cell size distributions, mean cell sizes, and cell densities are shown in Figure 5. The SEM images of the cross-sectioned foams qualitatively show that neat PLA foams (Figure 4a) have a poor-quality foam morphology with many coalesced and 

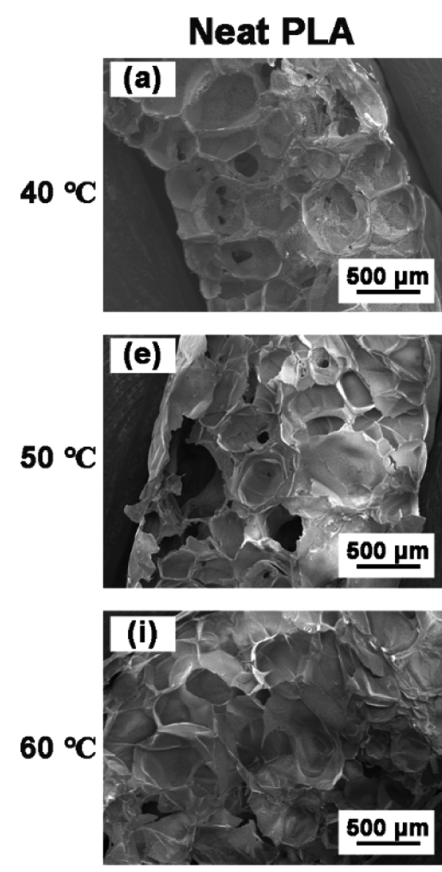

PLA-1\%-CNC
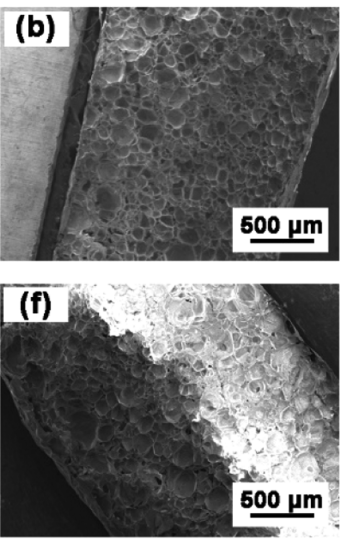

PLA-3\%-CNC
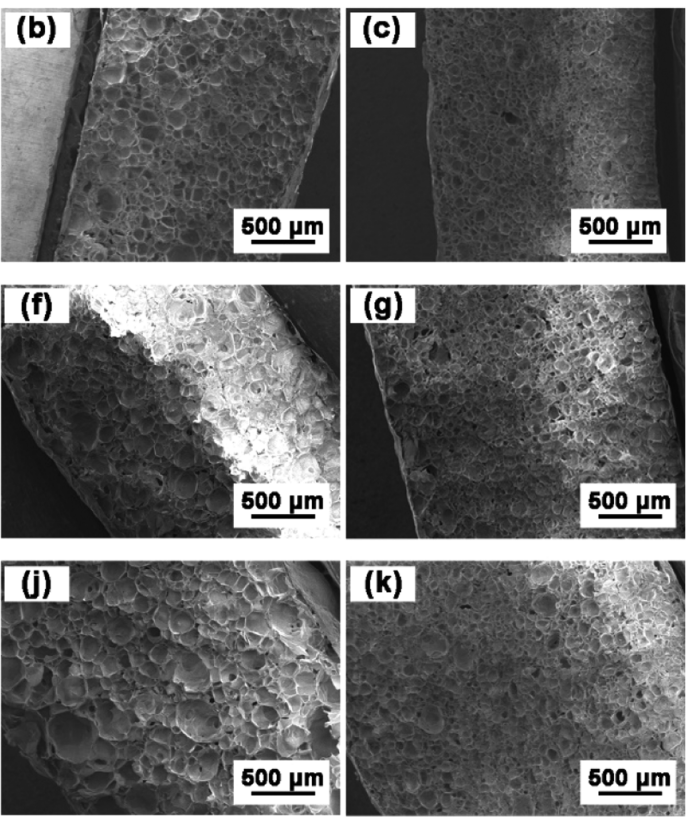

\section{PLA-5\%-CNC}
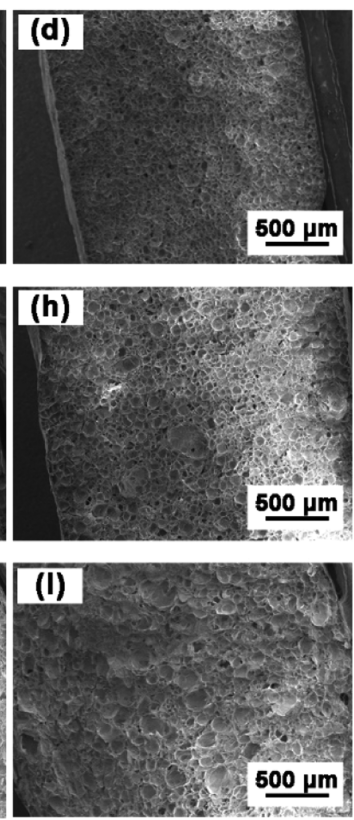

Figure 6. SEM images of cross-sectioned PLA/CNC composite foams as a function of the CNC loading and foaming temperature. The CNC loading was between 0 and $5 \mathrm{wt} \%$, and the foaming temperature was $40{ }^{\circ} \mathrm{C}(\mathrm{a}-\mathrm{d}), 50{ }^{\circ} \mathrm{C}(\mathrm{e}-\mathrm{h})$, or $60^{\circ} \mathrm{C}(\mathrm{i}-\mathrm{l})$.
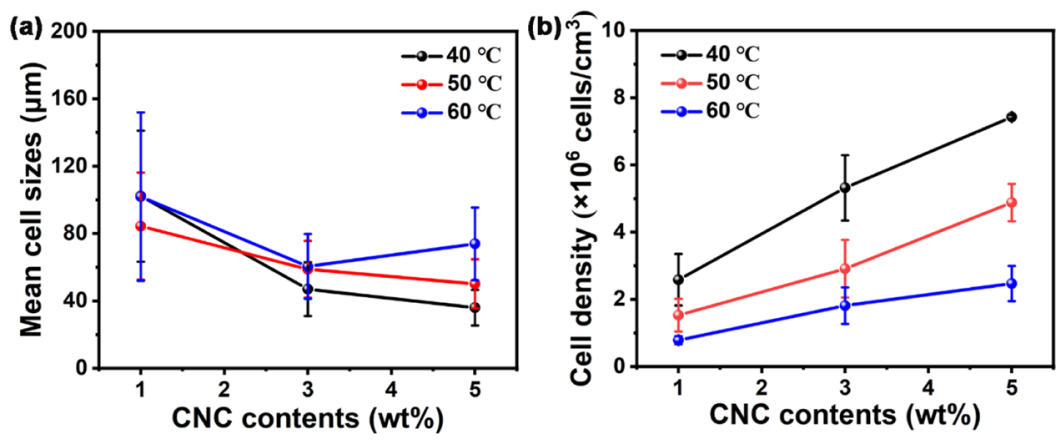

Figure 7. Mean cell size (a) and cell density (b) of PLA/CNC composite foams prepared at different foaming temperatures.

collapsed cells. ${ }^{45}$ Upon adding up to 5 wt \% CNCs by the Pickering emulsion masterbatch route, the PLA/CNC composite foams have a decreased cell size with an increased cell density. As shown in Figure S6a-d, it is observed that the cell size distribution becomes narrower as the CNC content increases. PLA/CNC foams obtained from the composites prepared by the masterbatch route with a CNC content of $5 \mathrm{wt}$ $\%$ had the lowest mean cell size $(36 \mu \mathrm{m}$, see Figure $5 \mathrm{a})$ and the narrowest cell size distribution, i.e., with cell sizes between 15 and $86 \mu \mathrm{m}$. In addition, the cell density of the PLA/CNC composite foams increased from $2.6 \times 10^{6}$ to $7.4 \times 10^{6}$ cells/ $\mathrm{cm}^{3}$ upon increasing the CNC content from 1 to $5 \mathrm{wt} \%$, respectively (see Figure $5 b$ ). We attribute the decrease in cell size, narrower cell size distribution, and increased cell density values for PLA/CNC foams prepared by the masterbatch route to well-dispersed CNCs in the PLA matrix. This is related to more effective nucleation of many foam cells ${ }^{30,46}$ and to enhanced melt viscosity of PLA to moderate foam cell expansion.

In contrast, it is clear from Figures $4 \mathrm{e}-\mathrm{g}$ and 5 that PLA/ CNC composites prepared by direct melt blending show a modest decrease in cell size and that the cell density remained of the same order of magnitude as the cell density of the pristine PLA foams. Furthermore, the cell size distribution remained relatively broad. We attribute these observations to the poor CNC dispersion. As such, the number of potential nucleating sites is reduced, and the lower number of dispersed CNCs are less effective in reducing the cell growth. The volume expansion ratio of PLA/CNC composite foams prepared by different methods is shown in Table S1. Due to the higher viscosity, the composites prepared by the Pickering emulsion masterbatch route had a lower expansion ratio than the one prepared by direct melt blending.

We also foamed PLA/CNC composites with 5 wt \% CNC prepared by compression molding of CNC-covered PLA particles obtained by the Pickering emulsion templating route as a control experiment. To our surprise, these PLA/CNC composite films did not foam well (Figure 4h). A possible explanation for this poor foaming behavior is provided below. First, we note that CNCs remain at the surface of dried PLA spheres (diameter $20 \mu \mathrm{m}$ ) prepared by the Pickering emulsion method. Next, we assume that by compression molding in the absence of dispersive forces, CNCs form well-dispersed CNCrich domains at the fused particle interphases enclosing $\mathrm{CNC}$ poor domains (i.e., the former PLA sphere interior). This means that compression molding of the CNC-covered PLA 


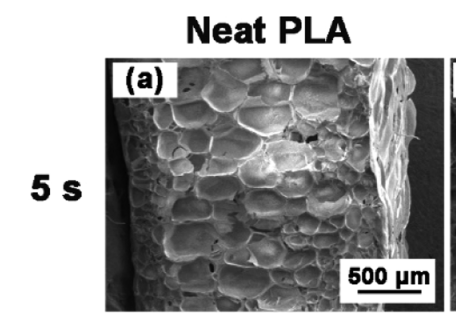

$10 \mathrm{~s}$
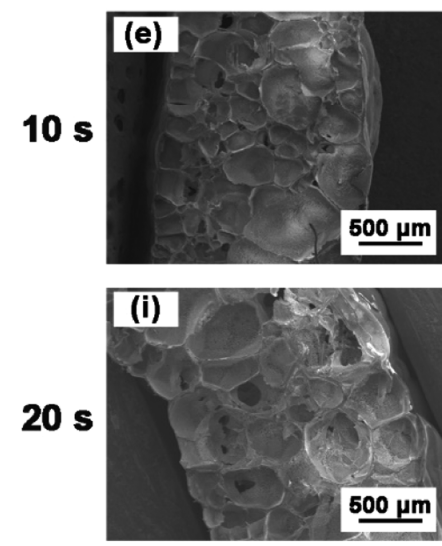

PLA-1\%-CNC
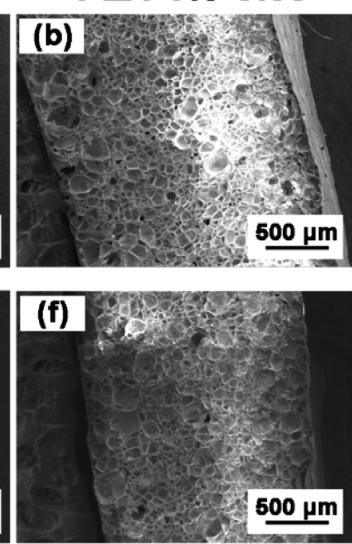

PLA-3\%-CNC
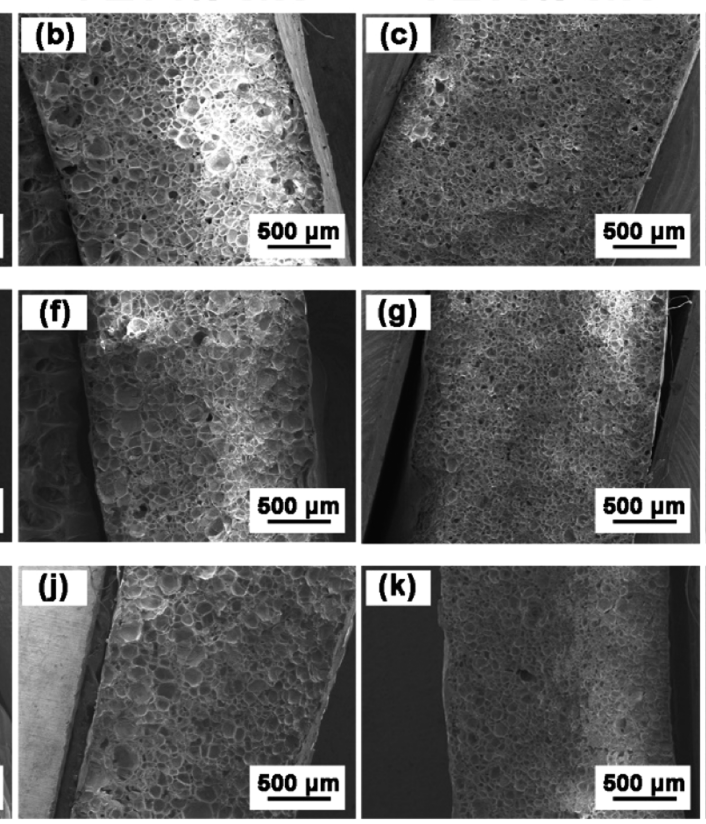

PLA-5\%-CNC
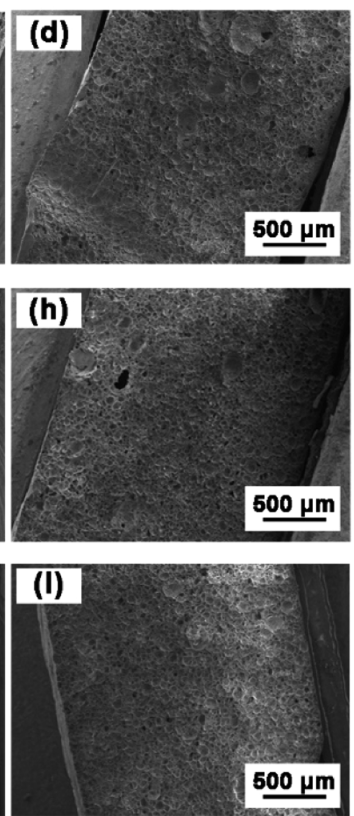

Figure 8. SEM images of cross-sectioned PLA/CNC composite foams as a function of the CNC loading and foaming time. The CNC loading values were between 0 and $5 \mathrm{wt} \%$ and the foaming times were $5 \mathrm{~s}(\mathrm{a}-\mathrm{d}), 10 \mathrm{~s}(\mathrm{e}-\mathrm{h})$, and $20 \mathrm{~s}(\mathrm{i}-\mathrm{l})$.
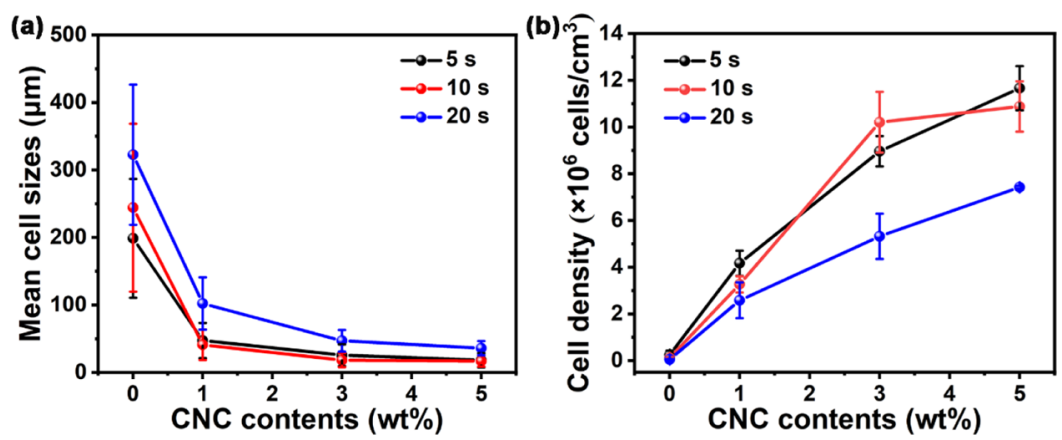

Figure 9. Mean cell size (a) and cell density (b) of PLA/CNC composite foams prepared with different foaming times.

spheres induces the formation of a network-like structure of $\mathrm{CNC}$-rich domains throughout the composite. In addition, the CNC-rich domains probably have a sufficiently high melt viscosity that foam cell expansion in the enclosed PLA-rich domains is hindered.

Based on the quantitative and qualitative foam morphology analysis presented and discussed above, we conclude that the Pickering emulsion masterbatch route provides a promising avenue for the dispersion of unmodified CNCs in a more hydrophobic PLA matrix. This opens possibilities to explore the effect of adding unmodified well-dispersed CNCs to PLA to further improve the foam morphology. The following two sections focus on PLA/CNC foams obtained by different foaming temperatures and foaming times.

Influence of Foaming Temperature on PLA/CNC Foaming. In addition to CNC dispersion and loading, the foaming temperature also has a significant influence on PLA foaming. Figure 6 shows SEM images of PLA/CNC films with a CNC loading of up to $5 \mathrm{wt} \%$ foamed at 40,50 , and $60{ }^{\circ} \mathrm{C}$. As shown in Figure 6, for a foaming temperature above $40{ }^{\circ} \mathrm{C}$, the cells of pristine PLA foams were ruptured due to fast cell growth or collapsed due to the lack of PLA melt strength. Remarkably, upon the addition of $1-5$ wt \% well-dispersed
CNCs, the melt strength of PLA in combination with the nucleating effect of CNCs resulted in the formation of PLA/ CNC foams with a closed-cell morphology.

Figure $7 \mathrm{a}$ shows the average cell size of the foams obtained at different temperatures. Upon increasing the foam temperature from 40 to $60{ }^{\circ} \mathrm{C}$, the mean cell size of PLA/CNC foams with 5 wt \% CNC increased from 36 to $74 \mu \mathrm{m}$, respectively. The cell size distribution of PLA/CNC composite foams with different $\mathrm{CNC}$ contents at different foaming temperatures is provided in Figure S7. The cell density (Figure 7b) of PLA/ CNC foams with 5 wt \% CNC decreased by $66.7 \%$ (from 7.4 $\times 10^{6}$ to $2.5 \times 10^{6}$ cells $/ \mathrm{cm}^{3}$ ) as the foaming temperature increased from 40 to $60{ }^{\circ} \mathrm{C}$. These observations were expected due to the increased cell expansion at higher foaming temperatures resulting in more cell coalescence and foam cell collapse. The volume expansion ratio of PLA/CNC composite foams as a function of the $\mathrm{CNC}$ loading and foaming temperature is shown in Table S2. Increasing the foaming temperature gave more energy to $\mathrm{CO}_{2}$ blown foam cell expansion and then the expansion ratio increased. In addition, it is clear from Figures 6 and 7 that the addition of unmodified CNCs to PLA matrices by the Pickering emulsion templated 
masterbatch route significantly broadens the processing window for PLA foaming.

Influence of Foaming Time on the PLA/CNC Foam Morphology. We investigated the influence of foaming time on the PLA/CNC foam morphology development to establish a processing window for the batch foaming of our PLA/CNC composites. Figure 8 shows SEM images of cross-sectioned PLA/CNC foams obtained during 5, 10, or 20 s, respectively. Figure 9 shows the corresponding mean cell size and cell density values of PLA/CNC foams (cell size distributions are provided in Figure S8). From the quantitative analysis presented in Figure 9, it is clear that the foam morphologies are comparable for materials obtained at foaming times of 5 and $10 \mathrm{~s}$. Upon increasing the foaming time, the cell size increases significantly while the cell density decreases. For instance, the cell size increased from 18 to $36 \mu \mathrm{m}$, and the cell density decreased from $11.7 \times 10^{6}$ to $7.4 \times 10^{6} \mathrm{cells} / \mathrm{cm}^{3}$, upon increasing the foaming time from 5 to $20 \mathrm{~s}$ for PLA/CNC composites with 5 wt \% CNCs, respectively. These observations are explained by an increasing foam cell coalescence at longer foaming times.

Overall, we conclude that the cell morphology of PLA/CNC foams is readily adjusted by changing the foaming temperature and time between $40-60{ }^{\circ} \mathrm{C}$ and 5-10 s, respectively, for the given saturation pressure (40 bar) and saturation time $(6 \mathrm{~h})$. Foaming at $40{ }^{\circ} \mathrm{C}$ for $5 \mathrm{~s}$ resulted in PLA/CNC foams with the lowest mean cell size $(\sim 18 \mu \mathrm{m})$ and highest cell density $\left(\sim 11.7 \times 10^{6}\right)$. The volume expansion ratio of PLA/CNC composite foams as a function of foaming time is shown in Table S3. The composites foamed for $5 \mathrm{~s}$ had the lowest expansion ratio. However, the composites foamed for $10 \mathrm{~s}$ had a similar expansion ratio to those for $20 \mathrm{~s}$. Compared to the previous studies of PLA/cellulose composite foams, ${ }^{23-25,30,47-51}$ the materials in this work are obtained at low saturation pressure and low foaming temperature, and have a low mean cell size and good cell density.

\section{CONCLUSIONS}

We prepared PLA/CNC composites with up to 5 wt \% welldispersed unmodified CNCs by the Pickering emulsion masterbatch route. In addition, we demonstrated that these unmodified CNCs were successful in foam cell nucleation and foam cell stabilization. The foam morphology was readily tuned by the CNC content, foaming temperature, and foaming time. When CNCs were not uniformly dispersed in the PLA matrix, as observed by direct melt blending and Pickering emulsion templating, the resulting foam morphologies were not well developed within the evaluated processing window. This is either attributed to having a lower number of effective CNC particles as nucleating agents present in the PLA matrix or to forming CNC-rich and CNC-poor domains by the blending methods. Overall, we show that the Pickering emulsion templating masterbatch route allows incorporating a hydrophilic filler in a hydrophobic thermoplastic matrix, which can be easily generalized to other filler/thermoplastic matrix systems.

\section{ASSOCIATED CONTENT}

\section{S1 Supporting Information}

The Supporting Information is available free of charge at https://pubs.acs.org/doi/10.1021/acsapm.1c01046.
SEM images of cross-sectioned PLA/CNC composites and AFM images of CNCs deposited at silicon substrates; tensile properties, $\mathrm{CO}_{2}$ absorption, crystallization properties, and volume expansion ratio of PLA/ CNC composite foams; and cell size distribution of PLA/CNC composite foams (PDF)

\section{AUTHOR INFORMATION}

\section{Corresponding Authors}

Joost Duvigneau - Materials Science and Technology of Polymers, MESA+ Institute for Nanotechnology, University of Twente, 7500 AE Enschede, The Netherlands; (1) orcid.org/ 0000-0002-2810-2768; Email: j.duvigneau@utwente.nl

Xiaofeng Sui - Key Laboratory of Science and Technology of Eco-Textile, Ministry of Education, College of Chemistry, Chemical Engineering and Biotechnology, Donghua University, Shanghai 201620, China; Email: suixf@ dhu.edu.cn

G. Julius Vancso - Key Laboratory of Science and Technology of Eco-Textile, Ministry of Education, College of Chemistry, Chemical Engineering and Biotechnology, Donghua University, Shanghai 201620, China; Materials Science and Technology of Polymers, MESA+ Institute for

Nanotechnology, University of Twente, 7500 AE Enschede, The Netherlands; (1) orcid.org/0000-0003-4718-0507; Email: g.j.vancso@utwente.nl

Author

Yunchong Zhang - Key Laboratory of Science and Technology of Eco-Textile, Ministry of Education, College of Chemistry, Chemical Engineering and Biotechnology, Donghua University, Shanghai 201620, China; Materials Science and Technology of Polymers, MESA+ Institute for Nanotechnology, University of Twente, 7500 AE Enschede, The Netherlands; (1) orcid.org/0000-0002-7057-9922

Complete contact information is available at:

https://pubs.acs.org/10.1021/acsapm.1c01046

\section{Author Contributions}

Y.Z.: methodology, experiments, data analysis, and writingoriginal draft; J.D.: methodology, supervision, and revising the paper; X.S.: methodology, supervision, revising the paper, and funding acquisition; and G.J.V.: supervision and revising the paper.

Notes

The authors declare no competing financial interest.

\section{ACKNOWLEDGMENTS}

The authors thank the MESA+ Institute for Nanotechnology of the University of Twente for financial support. Y.Z. expresses his appreciation to the Chinese Scholarship Council for graduate studies scholarship (No. 201906630095). The authors also thank Clemens Padberg for obtaining the SEM images.

\section{REFERENCES}

(1) Chen, L.; Rende, D.; Schadler, L. S.; Ozisik, R. Polymer Nanocomposite Foams. J. Mater. Chem. A 2013, 1, 3837-3850.

(2) Liu, S.; Duvigneau, J.; Vancso, G. J. Nanocellular Polymer Foams as Promising High Performance Thermal Insulation Materials. Eur. Polym. J. 2015, 65, 33-45. 
(3) Abbasi, H.; Antunes, M.; Velasco, J. I. Recent Advances in Carbon-Based Polymer Nanocomposites for Electromagnetic Interference Shielding. Prog. Mater. Sci. 2019, 103, 319-373.

(4) Paruzel, A.; Michałowski, S.; Hodan, Ji.; Horák, P.; Prociak, A.; Beneš, H. Rigid Polyurethane Foam Fabrication Using Medium Chain Glycerides of Coconut Oil and Plastics From End-of-Life Vehicles. ACS Sustainable Chem. Eng. 2017, 5, 6237-6246.

(5) Jacobs, L. J.; Kemmere, M. F.; Keurentjes, J. T. Sustainable Polymer Foaming Using High Pressure Carbon Dioxide: a Review on Fundamentals, Processes and Applications. Green Chem. 2008, 10, $731-738$.

(6) Le Moigne, N.; Sauceau, M.; Benyakhlef, M.; Jemai, R.; Bénézet, J.-C.; Rodier, E.; Lopez-Cuesta, J.-M.; Fages, J. Foaming of Poly (3hydroxybutyrate-co-3-hydroxyvalerate)/Organo-Clays Nano-Biocomposites by A Continuous Supercritical $\mathrm{CO}_{2}$ Assisted Extrusion Process. Eur. Polym. J. 2014, 61, 157-171.

(7) Livi, Sb.; C Lins, L.; Sar, G.; Gérard, J.-F. o.; Duchet-Rumeau, J. Supercritical $\mathrm{CO}_{2}$-Ionic Liquids: A Successful Wedding to Prepare Biopolymer Foams. ACS Sustainable Chem. Eng. 2016, 4, 461-470.

(8) Wang, X.; Pan, Y.; Liu, X.; Liu, H.; Li, N.; Liu, C.; Schubert, D. W.; Shen, C. Facile Fabrication of Superhydrophobic and EcoFriendly Poly (lactic acid) Foam for Oil-Water Separation via Skin Peeling. ACS Appl. Mater. Interfaces 2019, 11, 14362-14367.

(9) Drumright, R. E.; Gruber, P. R.; Henton, D. E. Polylactic Acid Technology. Adv. Mater. 2000, 12, 1841-1846.

(10) Saeidlou, S.; Huneault, M. A.; Li, H.; Park, C. B. Poly (lactic acid) Crystallization. Prog. Polym. Sci. 2012, 37, 1657-1677.

(11) Fairag, R.; Rosenzweig, D. H.; Ramirez-Garcialuna, J. L.; Weber, M. H.; Haglund, L. Three-Dimensional Printed Polylactic Acid Scaffolds Promote Bone-Like Matrix Deposition in Vitro. ACS Appl. Mater. Interfaces 2019, 11, 15306-15315.

(12) Nofar, M.; Park, C. B. Poly (lactic acid) Foaming. Prog. Polym. Sci. 2014, 39, 1721-1741.

(13) Kuang, T.-R.; Mi, H.-Y.; Fu, D.-J.; Jing, X.; Chen, B.-y.; Mou, W.-J.; Peng, X.-F. Fabrication of Poly (lactic acid)/Graphene Oxide Foams with Highly Oriented and Elongated Cell Structure via Unidirectional Foaming Using Supercritical Carbon Dioxide. Ind. Eng. Chem. Res. 2015, 54, 758-768.

(14) Ji, G.; Zhai, W.; Lin, D.; Ren, Q.; Zheng, W.; Jung, D. W. Microcellular Foaming of Poly (lactic acid)/Silica Nanocomposites in Compressed $\mathrm{CO}_{2}$ : Critical Influence of Crystallite Size on Cell Morphology and Foam Expansion. Ind. Eng. Chem. Res. 2013, 52, 6390-6398.

(15) Zhao, M.; Ding, X.; Mi, J.; Zhou, H.; Wang, X. Role of HighDensity Polyethylene in the Crystallization Behaviors, Rheological Property, and Supercritical $\mathrm{CO}_{2}$ Foaming of Poly (lactic acid). Polym. Degrad. Stab. 2017, 146, 277-286.

(16) Ren, Q.; Wang, J.; Zhai, W.; Lee, R. E. Fundamental Influences of Induced Crystallization and Phase Separation on the Foaming Behavior of Poly (lactic acid)/Polyethylene Glycol Blends Blown with Compressed $\mathrm{CO}_{2}$. Ind. Eng. Chem. Res. 2016, 55, 12557-12568.

(17) Mihai, M.; Huneault, M. A.; Favis, B. D. Rheology and Extrusion Foaming of Chain-Branched Poly (lactic acid). Polym. Eng. Sci. 2010, 50, 629-642.

(18) Di, Y.; Iannace, S.; Di Maio, E.; Nicolais, L. Reactively Modified Poly (lactic acid): Properties and Foam Processing. Macromol. Mater. Eng. 2005, 290, 1083-1090.

(19) Salerno, A.; Domingo, C. Low-Temperature Clean Preparation of Poly (lactic acid) Foams by Combining Ethyl Lactate and Supercritical $\mathrm{CO}_{2}$ : Correlation Between Processing and Foam Pore Structure. Polym. Int. 2014, 63, 1303-1310.

(20) Ema, Y.; Ikeya, M.; Okamoto, M. Foam Processing and Cellular Structure of Polylactide-based Nanocomposites. Polymer 2006, 47, 5350-5359.

(21) Keshtkar, M.; Nofar, M.; Park, C. B.; Carreau, P. Extruded PLA/Clay Nanocomposite Foams Blown with Supercritical $\mathrm{CO}_{2}$. Polymer 2014, 55, 4077-4090.
(22) Liu, L.; Fan, X.; Zhang, Y.; Zhang, S.; Wang, W.; Jin, X.; Tang, B. Novel Bio-Based Phase Change Materials with High Enthalpy for Thermal Energy Storage. Appl. Energy 2020, 268, No. 114979.

(23) Ding, W.; Kuboki, T.; Wong, A.; Park, C. B.; Sain, M. Rheology, Thermal Properties, and Foaming Behavior of High dcontent Polylactic Acid/Cellulose Nanofiber Composites. RSC Adv. 2015, 5, 91544-91557.

(24) Dlouhá, J.; Suryanegara, L.; Yano, H. Cellulose Nanofibre-Poly (lactic acid) Microcellular Foams Exhibiting High Tensile Toughness. React. Funct. Polym. 2014, 85, 201-207.

(25) Dlouhá, J.; Suryanegara, L.; Yano, H. The Role of Cellulose Nanofibres in Supercritical Foaming of Polylactic Acid and Their Effect on the Foam Morphology. Soft Matter 2012, 8, 8704-8713.

(26) Vatansever, E.; Arslan, D.; Nofar, M. Polylactide CelluloseBased Nanocomposites. Int. J. Biol. Macromol. 2019, 137, 912-938.

(27) Borkotoky, S. S.; Dhar, P.; Katiyar, V. Biodegradable Poly (lactic acid)/Cellulose Nanocrystals (CNCs) Composite Microcellular Foam: Effect of Nanofillers on Foam Cellular Morphology, Thermal and Wettability Behavior. Int. J. Biol. Macromol. 2018, 106, 433-446.

(28) Lin, N.; Huang, J.; Chang, P. R.; Feng, J.; Yu, J. Surface Acetylation of Cellulose Nanocrystal and Its Reinforcing Function in Poly (lactic acid). Carbohydr. Polym. 2011, 83, 1834-1842.

(29) Goffin, A.-L.; Raquez, J.-M.; Duquesne, E.; Siqueira, G.; Habibi, Y.; Dufresne, A.; Dubois, P. From Interfacial Ring-Opening Polymerization to Melt Processing of Cellulose Nanowhisker-filled Polylactide-based Nanocomposites. Biomacromolecules 2011, 12, $2456-2465$.

(30) Qiu, Y.; Lv, Q.; Wu, D.; Xie, W.; Peng, S.; Lan, R.; Xie, H. Cyclic Tensile Properties of the Polylactide Nanocomposite Foams Containing Cellulose Nanocrystals. Cellulose 2018, 25, 1795-1807.

(31) Zhang, Y.; Cui, L.; Xu, H.; Feng, X.; Wang, B.; Pukánszky, B.; Mao, Z.; Sui, X. Poly (lactic acid)/Cellulose Nanocrystal Composites via the Pickering Emulsion Approach: Rheological, Thermal and Mechanical Properties. Int. J. Biol. Macromol. 2019, 137, 197-204.

(32) Zhang, Y.; Jiang, Y.; Han, L.; Wang, B.; Xu, H.; Zhong, Y.; Zhang, L.; Mao, Z.; Sui, X. Biodegradable Regenerated CelluloseDispersed Composites with Improved Properties via A Pickering Emulsion Process. Carbohydr. Polym. 2018, 179, 86-92.

(33) Zhang, Y.; Wu, J.; Wang, B.; Sui, X.; Zhong, Y.; Zhang, L.; Mao, $\mathrm{Z}$; $\mathrm{Xu}, \mathrm{H}$. Cellulose Nanofibril-Reinforced Biodegradable Polymer Composites Obtained via A Pickering Emulsion Approach. Cellulose 2017, 24, 3313-3322.

(34) Li, X.; Hegyesi, N.; Zhang, Y.; Mao, Z.; Feng, X.; Wang, B.; Pukánszky, B.; Sui, X. Poly (lactic acid)/Lignin Blends Prepared with the Pickering Emulsion Template Method. Eur. Polym. J. 2019, 110, 378-384.

(35) Xu, L.-Q.; Huang, H.-X. Foaming of Poly (lactic acid) Using Supercritical Carbon Dioxide as Foaming Agent: Influence of Crystallinity and Spherulite Size on Cell Structure and Expansion Ratio. Ind. Eng. Chem. Res. 2014, 53, 2277-2286.

(36) Qu, Z.; Yin, D.; Zhou, H.; Wang, X.; Zhao, S. Cellular Morphology Evolution in Nanocellular Poly (lactic acid)/Thermoplastic Polyurethane Blending Foams in the Presence of Supercritical $\mathrm{N}_{2}$. Eur. Polym. J. 2019, 116, 291-301.

(37) Zhang, W.; Chen, B.; Zhao, H.; Yu, P.; Fu, D.; Wen, J.; Peng, X. Processing and Characterization of Supercritical $\mathrm{CO}_{2}$ Batch Foamed Poly (lactic acid)/Poly (ethylene glycol) Scaffold for Tissue Engineering Application. J. Appl. Polym. Sci. 2013, 130, 3066-3073.

(38) Kumar, V.; Suh, N. P.; Process, A. A Process for Making Microcellular Thermoplastic Parts. Polym. Eng. Sci. 1990, 30, 13231329.

(39) Kalashnikova, I.; Bizot, H.; Cathala, B.; Capron, I. Modulation of Cellulose Nanocrystals Amphiphilic Properties to Stabilize Oil/ Water Interface. Biomacromolecules 2012, 13, 267-275.

(40) Arias, A.; Heuzey, M.-C.; Huneault, M. A.; Ausias, G.; Bendahou, A. Enhanced Dispersion of Cellulose Nanocrystals in MeltProcessed Polylactide-Based Nanocomposites. Cellulose 2015, 22, 483-498. 
(41) Dhar, P.; Bhasney, S. M.; Kumar, A.; Katiyar, V. Acid Functionalized Cellulose Nanocrystals and Its Effect on Mechanical, Thermal, Crystallization and Surfaces Properties of Poly (lactic acid) Bionanocomposites Films: A Comprehensive Study. Polymer 2016, 101, 75-92.

(42) Li, B.; Zhao, G.; Wang, G.; Zhang, L.; Gong, J. Fabrication of High-Expansion Microcellular PLA Foams Based on Pre-isothermal Cold Crystallization and Supercritical $\mathrm{CO}_{2}$ Foaming. Polym. Degrad. Stab. 2018, 156, 75-88.

(43) Arslan, D.; Vatansever, E.; Sarul, D. S.; Kahraman, Y.; Gunes, G.; Durmus, A.; Nofar, M. Effect of Preparation Method on the Properties of Polylactide/Cellulose Nanocrystal Nanocomposites. Polym. Compos. 2020, 41, 4170-4180.

(44) Yin, Y.; Zhao, L.; Jiang, X.; Wang, H.; Gao, W. Cellulose Nanocrystals Modified with A Triazine Derivative and Their Reinforcement of Poly (lactic acid)-Based Bionanocomposites. Cellulose 2018, 25, 2965-2976.

(45) Wang, J.; Chai, J.; Wang, G.; Zhao, J.; Zhang, D.; Li, B.; Zhao, H.; Zhao, G.S. Strong and Thermally Insulating Polylactic Acid/Glass Fiber Composite Foam Fabricated by Supercritical Carbon Dioxide Foaming. Int. J. Biol. Macromol. 2019, 138, 144-155.

(46) Zheng, T.; Pilla, S. Melt Processing of Cellulose NanocrystalFilled Composites: Toward Reinforcement and Foam Nucleation. Ind. Eng. Chem. Res. 2020, 59, 8511-8531.

(47) Boissard, C. I.; Bourban, P.-E.; Plummer, C. J. G.; Neagu, R. C.; Månson, J.-A. E. Cellular Biocomposites from Polylactide and Microfibrillated Cellulose. J. Cell. Plast. 2012, 48, 445-458.

(48) Zimmermann, M. V.; da Silva, M. P.; Zattera, A. J.; Santana, R. M. Poly (lactic acid) Foams Reinforced with Cellulose Micro and Nanofibers and Foamed by Chemical Blowing Agents. J. Cell. Plast. 2018, 54, 577-596.

(49) Cho, S. Y.; Park, H. H.; Yun, Y. S.; Jin, H.-J. Influence of Cellulose Nanofibers on the Morphology and Physical Properties of Poly (lactic acid) Foaming by Supercritical Carbon Dioxide. Macromol. Res. 2013, 21, 529-533.

(50) Kang, D. J.; Xu, D.; Zhang, Z. X.; Pal, K.; Bang, D. S.; Kim, J. K. Well-Controlled Microcellular Biodegradable PLA/Silk Composite Foams Using Supercritical $\mathrm{CO}_{2}$. Macromol. Mater. Eng. 2009, 294, $620-624$.

(51) Matuana, L.; Faruk, O. Effect of Gas Saturation Conditions on the Expansion Ratio of Microcellular Poly (lactic acid)/Wood-Flour Composites. Express Polym. Lett. 2010, 4, 621-631.

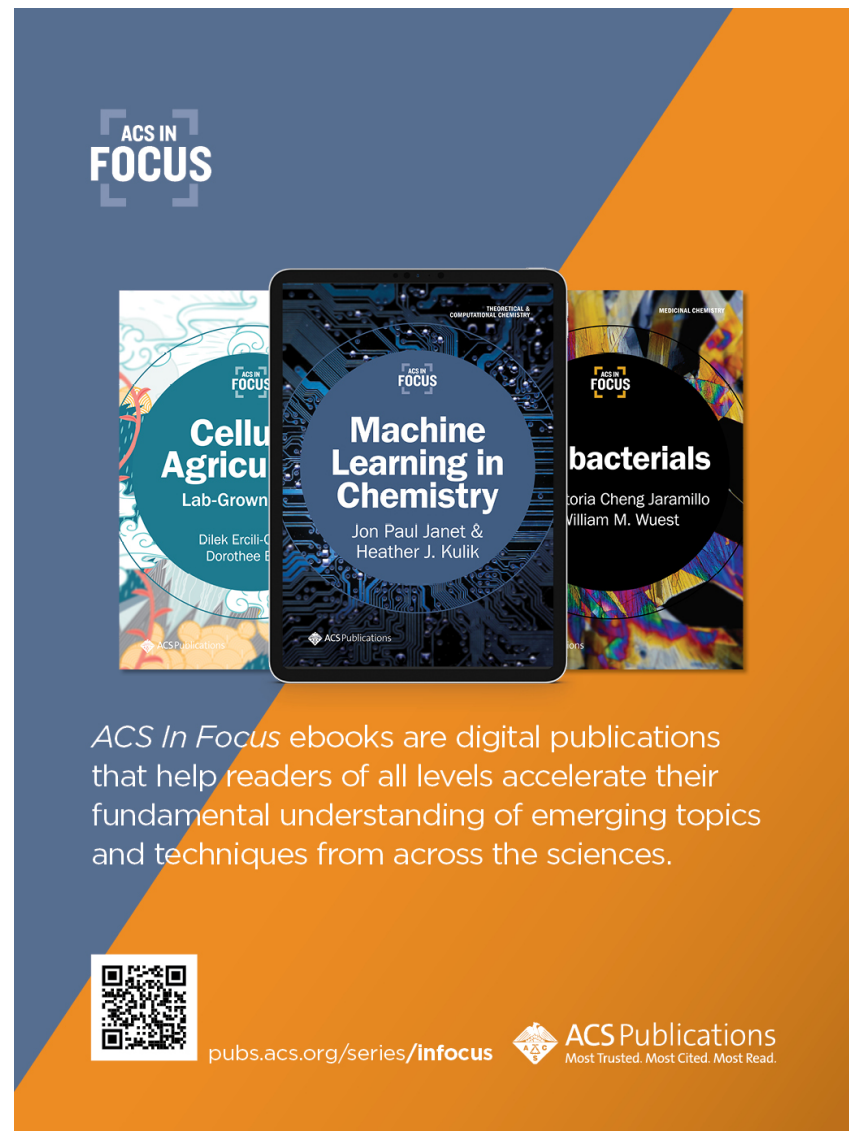

